\title{
Research on Engineering Undergraduate Practice Teaching Model Based on Trinity
}

\author{
Shan Jing ${ }^{1, a}$ Runyuan Sun ${ }^{1, b}$ Xiaomei Yu ${ }^{1, c}$ Changwen Lu ${ }^{2, d}$ \\ ${ }^{1}$ Shandong Provincial Key Laboratory of Network Based Intelligent Computing, \\ Jinan, P. R. China, 250022 \\ ${ }^{2}$ School of Information Science and Engineering, University of Jinan, \\ Jinan, P. R. China, 250022 \\ a.jingshan@ujn.edu.cn; b.sunry@ujn.edu.cn; c.nic_yuxm@ujn.edu.cn; \\ d.sean_lcw@qq.com
}

\begin{abstract}
In this paper, combining the reform of network engineering major in the University of Jinan, We explore a kind of new practice teaching model, which is a trinity based on the point, line, and plane. In the three constructions, the point is the each course which is the basis of practice, the line is the every direction of specialty which is a main line, and the plane is the system of training which is a cover of whole link. The trinity model is used to comprehensively improve the practice teaching level in specialty and make whole practice training system more reasonable and effective, and provide practical implementation experience.
\end{abstract}

Keywords: Trinity; Practice Teaching; Engineering

\section{Introduction}

With the rapid development of information network technology, training senior practical network talents becomes very important. The network engineering major's main aim is to train student to obtain various engineering application ability, so the construction of practice teaching is very important to this. The tradi- tional learning and teaching model is limited by time and resource, which cannot satisfy the need of the society for innovative and practical talents.

Combining with the revision of network engineering undergraduate training program on University of Jinan in Shandong province and the construction work of higher school characteristic profession, it researches and practice specifically network engineering professional practice teaching model.

The network engineering profession in the University of Jinan began to recruit students in 2003, which are the second batch colleges and universities for approving to set up network engineering professional all over the nation. Through the construction and development in the ten years, it becomes the college characteristic specialty in Shandong province in 2012.

\section{Present situation analysis of profes- sional training system in network engineering}

At present, University of Jinan implements training mode in accordance with the combination of subject categories enrollment and professional shunt, the professional personnel training of network 
engineering is divided into the "threestep" structure: in the first stage, it needs one year for finishing basic knowledge training, which mainly launches the general course, the basic course of subject and professional introduction course. Then, the second stage should be two years to complete the basic ability training, students sorting professional and complete professional course study. Last, in the third stage, it needs to complete the training in comprehensive practice ability in the last year, open modular, comprehensive direction optional practice course for providing more choices to students on professional direction.

Based on the "1-2-1" mode of threestep personnel training, it pays more attention to the students' basic knowledge and ability training.

\section{The trinity practice teaching mode}

Trinity practice teaching mode comprehensively improves the teaching level of profession practice and further deepens the reform of practice teaching in the course of training system, which pays attention to point, line and plane as a trinity. In the three constructions, the point is the each course which is the basis of practice, the line is the every direction of specialty which is a main line, and the plane is the system of training which is a cover of whole link. The trinity model is used to comprehensively improve the practice teaching level of specialty and make whole practice training system more reasonable and effective. Consequently, graduates will be more suitable for enterprises and institutions for the need of technique talented person with engineering skills. The Trinity practice teaching mode is feasible in bringing students' main body effect into full play as well as making apparent function in cultivating students' engineering capability and inno- vation ability [1]. Fig. 1 shows the trinity practice teaching mode.

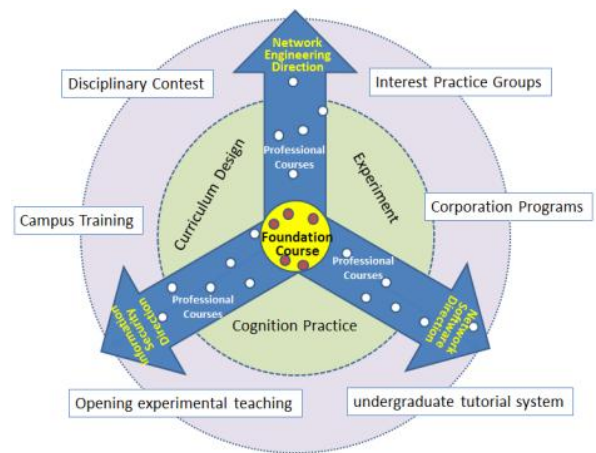

Fig. 1: trinity practice teaching system structure diagram

\subsection{Points: each course}

Course is the foundation of the whole training system, the practice of the course is also the foundation and core of the practice model.

Curriculum practice includes course experiment and curriculum design, and the common feature of both is to deepen and to extend the theoretical knowledge of a course. Experiment is mainly used to make students better grasp the content of course, but the curriculum design emphasize more on comprehensive and designing, arranging the specific experiment from simple to complicated and from a single to comprehensive way. Classroom practice is mainly based on the verification experiment and the operating configuration experiment, through the experiment, the students can deepen their understanding about the content and master the basic use of tools and complete simple project scheme design and implementation.

\subsection{Line: three major directions}

Combining local demand for talents and the actual situation in University of Jinan, network engineering major set up three directions, including network engineering construction and management, network software design and development, and the 
network and information security. In each direction, student needs to realize the content from basic to comprehensive, from general to specific, knowledge platform to realize a hierarchical culture.

- The goal of the network engineering construction and management is to develop the students' abilities of mastering integrated wiring related technologies, grasping the system integration method and process, designing small-size and medium-sized network, and configuring and maintaining the network equipment and the servers, and practicing on other aspects, such as the wireless network technology, VPN, IPv6, etc.. After graduation, students can be engaged in network planning and design, network management in enterprises or institutions.

- The cultivating goal of network software design and development direction is to be familiar with the information system development framework, master Java, .Net development language and platform, master database application technology, software engineering, etc., and after graduation, students can work on information system development and maintenance in enterprises or institutions.

- The cultivating goal of network and information security direction is to make students obtain the ability to master the basic concept and principle applied cryptography, be familiar with the PKI system and application, be familiar with common network security vulnerabilities and preventive measures. After graduation, students can be engaged in research and development in network security area.

According to the major direction, specialized courses can be roughly divided into three main line, the formation of whom also makes the teachers and students more clearly about the course of theoretical knowledge and practical con- tents carding. After entering the second grade, offering specialty basic courses to students mostly, paying attention to the basic theoretical knowledge, and providing a small amount of confirmatory basic practice to help students understand the knowledge. In the third grade, with the support of the professional basic knowledge, students begin their major course study in specialty direction. In this stage, a lot of specialty required courses, elective courses and free course are opened for students to choose. These courses attach importance to the practice content and practice method of training, and consequently can improve students' comprehensive practice ability level partly.

In the final undergraduate year, we pay most attention to cultivate students' practical abilities, providing students with more specific and task-based practical goal by means of professional training process and graduation design. Meeting the need of engineering practice, the students carry out practice in "team-work" mode, with the specialty basic knowledge and practical ability, which gives full play to the initiative of learning. At the same time, the vivid cases enhance the interest in learning and make students enjoy the process.

\subsection{Plane: diversification practice mode}

Strengthening the network engineering practice and the personalized, diversified training methods have an important meaning, the diversity of practical training, as a extension on practice training system, has a great meaning in guiding the students to participate in the practice, enriching practical means, improving the practice effect, promoting the reform of practice teaching system.

(1) Introducing corporation programs. Not only the colleges and universities strive to train talents, but also the enter- 
prises are making effort to cultivate outstanding engineering and technical personnel.

Through the collaboration with wellknown both at home and abroad enterprises, we introduce a lot practical teaching platforms, including Cisco, Huawei, Oracle, Redhat, Inspur and so on. Through studying and optimizing corporate programs, we set up them as the specialty courses in the second stage. These courses enhance the students' interest in learning and generally get very good effect in the teaching.

(2) Carrying out campus training. Practical training means "practice" and "train", emphasizing on managerial practice and technical practice. The training content is highly targeted to graduates on employment, which is deeply popular with students. Consequently, network engineering strengthens the cooperation with the training institutions, professional training is offered by teachers and lecturers in training unit who can combine with the market's demand, improves the professional practice teaching level, enhances students' practical abilities, and also improves graduates employment rate.

(3) Founding students' interest practice groups. The University of Jinan has abundant teaching resources of the network and practice platform. We organize students to participate in the campus network management in the mode of interest practice groups, through the cooperation with the school network center. Under the guidance of teachers with rich experience in network management, students carry out professional practice, and in recent years, have completed the network construction in both teachers' and students' dormitory network, construction of IPv6 test network, development of the campus network information system and development of various websites. Students had greatly developed comprehensive practice abilities.
(4) Disciplinary Contest. Disciplinary Contest practice teaching based on competition is highly praised as a good training way by many colleges and universities, the students have also greatly interest to participating. In the professional skills competition, driven by enterprise and industry, students cultivate strong teamspirit and improve the technical development and practice ability, through the preparation, development, verification, and testing of the entries. The way of the conversion from disciplinary contest content to practice teaching is proposed. The idea can improve the practice teaching content and cultivate the practice innovation capability of the college students [2].

(5) Opening experimental teaching. The degree of openness of the professional laboratory in universities is also related to its practice teaching level. The opening experimental teaching can make up for the shortcomings of traditional experimental teaching and enhance comprehensive ability of the students. The opening experiment teaching is a multidimension open in experimental time, experimental contents and experiment main body [3-4]. The purpose of opening experimental teaching is drawing more well-known entrepreneurs, outstanding alumni and students into laboratory. This mode provide students with platforms to see the development direction of social technology and the social need, through lectures, theme exchange, case simulation and other forms.

(6) Spreading undergraduate tutorial system [5]. To provide students with opportunity to make them participate deeply in teachers' scientific research, when the students enter the second stage, they make a major choice. For the students who enter the network engineering major, we distribute a teacher for each one. With the teacher's help, students accomplish the specialized courses, establishment of 
discipline direction, comprehensive practice guidance.

Undergraduate tutorial system make the students enhance the ability to actively find, analyze and solve problems, through participating in scientific research. For the senior students, the supervisor can guide them to carry on the employment preparation or take the postgraduate exams, improve the quality of graduates.

\subsection{Construct practice teaching sys- tem via the integration of point, line and plane}

Course is the foundation of the whole training system, the practice in curriculum is the core of the practice model. Practice within the course is mainly used to reinforce the understanding of basic knowledge. The same direction among different subjects should have very good cohesion, but cannot have too much repetition; it should reflect hierarchical structure based on depth and difficulty. A kind of knowledge point in certain specialty direction will not only cover a relatively complete knowledge system, but also reflect the changes of the modes of practice. From the basic verification type experiment knowledge development to integrated design type experiment, finally, it extends to design innovative experimental type, and the students have get a greatly development from imitated doing, thinking doing to researched doing.

Beyond building up the basic practice architecture, through the tutorial system, competition-driven practice teaching, students' interest practice group, the introduction of enterprise course, open laboratory, carry out the training and so on, many kinds of practice way unifies student and teacher in together, students and laboratory together, and thereby drive students to enter the laboratory and the practice teaching process. The student study activity is changed from passive to active, from task to interest; the practice effect is improved greatly.

\section{Conclusion}

Network engineering practice teaching should not just increase the theoretical teaching theory, What is important is that it is combined with the development of information society and the market demand, realize the construction of the trinity in three ways: course practice, specialty direction training and practice platform. Through the construction of the trinity, strengthening reform of the practice teaching method, improving practice teaching level, enhancing students' professional skills, promoting strain and practical abilities, consequently improving students' competiveness.

\section{Acknowledgements}

This work was supported by the Program for New Century Excellent Talents in University No.NCET-10-0863, the Teaching Research Foundation of University of Jinan No.J1131and No.JZC1138, and Curriculum Reform Pilot Project of University of Jinan No.BMKC11071.

\section{References}

[1] XU Lin, WU Chengdong, CHEN Dali, HUANG Da, and ZHAO Jing, "Exploration and Practice of Trinity Practice Teaching of Automation Specialty," Journal of Electrical \& Electronic Engineering Education, Vol.31, pp.56-68, 2009.

[2] LI Xiuzhen, CAO Qun, PANG Siping, "Experience in implementing opening experimental teaching," Experimental Technology and Management, Vol.2, pp. 140-142, 2008.

[3] Zhang Ruicheng, Chen Zhikun, Wang Fubin, "Exploration on the conversion 
from disciplinary contest content to practice teaching," Experimental Technology and Management, Vol. 27, pp.130-132, 2010.

[4] XU Xiaoming, ZHANG Xiangwei, DIN Zhen, MAO Zhiwei, and CHEN Shuhuai, "Opening Experimental Teaching Management Mode and System Fulfillment," Laboratory Research and Exploration, Vol. 26, pp.80-82, 2007.

[5] CHU Zengyong, OU Xuan, "Cultivate Innovative Talents in China' $\mathrm{s}$ Universities Using for Reference the Bachelor Tutor System in Oxford University," Journal of Higher Education Research, Vol. 35, pp.33-35, 2012. 